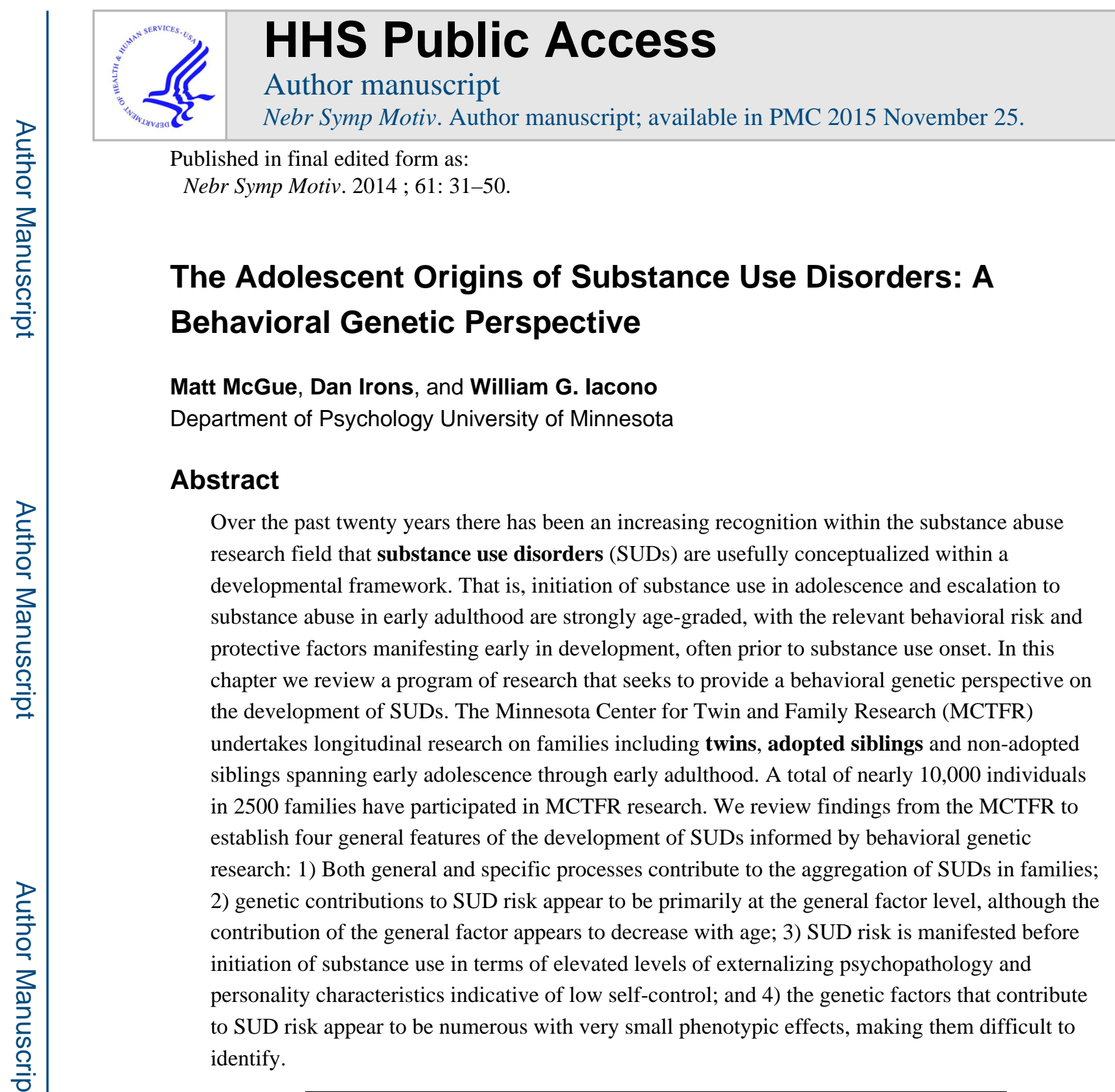

\title{
Introduction
}

One of the most important findings to emerge from the addictions research field over the past 20 years involves the recognition of the developmental nature of substance use disorders (SUDs) (Masten, Faden, Zucker, \& Spear, 2008). That is, trajectories of substance use that end in a SUD are strongly age-graded, with substance use typically beginning in early to middle adolescence, escalating to regular and problematic use in late adolescence, and progressing to the onset of a SUD in early adulthood. The impact of the relevant risk and protective factors are similarly conditioned by age. For example, indicators of SUD risk can be observed well before substance use initiation (Caspi, Moffitt, Newman, \& Silva, 1996), and normative developmental transitions constitute critical periods both for the onset

Correspondence: Matt McGue Department of Psychology University of Minnesota 75 East River Rd. Minneapolis, MN 55455 (612)-625-8305 (Voice); (612)-626-2079 (FAX) mcgue001@.umn.edu. 
of problematic substance use (e.g., the college years) as well as for its desistence (e.g., in early adulthood).

Here we describe a program of research that has contributed to the emerging developmental perspective on SUDs. A unique feature of this research is its behavioral genetic basis. We begin by describing the research context and then proceed to discussing four important sets of findings that have emerged from this program of research: 1) SUDs are highly comorbid, 2) there are both genetic and environmental contributions to the familial transmission of SUDs, 3) early to middle-adolescence is a critical period in the development of SUDs, and 4) it has been very difficult to identify the specific genetic variants that underlie the heritability of SUDs.

\section{The Research Context: The Minnesota Center for Twin and Family Research}

The Minnesota Center for Twin and Family Research (MCTFR) was established in 1990 when David Lykken and a team of researchers initiated a cross-sequential study of a sample of male adolescent twins. Over the nearly 25 years of its existence, the MCTFR has ascertained and assessed a total of nearly 10,000 individuals in approximately 2500 nuclear families. While the scope and range of MCTFR research has expanded over the years, the core mission of the MCTFR - to explore the origins of substance use disorders using longitudinal, family-based research designs - has not.

Figure 1 provides a schematic of the basic sampling unit used in the MCTFR studies, a nuclear family consisting of a pair of twins or siblings, first assessed in adolescence, and their rearing parents, who in many but not all cases were also their genetic parents. The families are distinguished by the relationship between the offspring, who are either monozygotic (MZ) twins, same-sex dizygotic (DZ) twins, full biological siblings, or nongenetically related but reared-together adopted siblings. Table 1 provides a brief overview of the three studies that constitute the core of the MCTFR. All of the studies implemented an intensive, day-long, in-person assessment that included substance use and SUDs, mental health disorders, individual-level risk factors including personality and cognitive ability, and environmental risk and protective factors including peers, family functioning, and life stress. Briefly, the Minnesota Twin Family Study (MTFS) is a longitudinal study of two cohorts (initially assessed at a target age of either 11 or 17 years) of MZ and like-sex DZ twins. These twins were ascertained from Minnesota state birth records and so are broadly representative of that US state. Additional details concerning the MTFS sampling design can be found in Iacono et al. (1999). The Sibling Interaction and Behavior Study (SIBS) is a longitudinal study of adoptive and non-adoptive families. Adoptive families were ascertained through records of adoption at three large adoption agencies in Minnesota, while non-adoptive families were ascertained through Minnesota records of birth. Additional details concerning the SIBS sampling design can be found in McGue et al. (2007). The Enrichment Study (ES) is a longitudinal study of a cohort of twins initially assessed at age 11. The ES broadly follows the ascertainment and assessment methods used in the MTFS with one significant difference. The ES sample was ascertained to over-represent twins who are at increased risk for developing a SUD by virtue of being high on a measure of 
externalizing psychopathology. Additional details concerning the ES sampling design can be found in Keyes et al. (2009).

Figure 2 provides a conceptual overview of the longitudinal follow-ups in the MCTFR studies, while Table 2 gives descriptive information about participants at each wave of assessment. Offspring follow-ups were targeted to occur every 3-4 years, at key transition points during the lives of young people. Follow-up of the initial participants has been generally high across the multiple waves of assessment, yielding a rich developmental dataset.

\section{Substance Use Disorders: Specific and General Effects}

One of the most salient features of SUDs is that they rarely occur in isolation. Individuals with a SUD typically abuse more than one substance (Martinotti et al., 2009) and often have other, non-substance related mental health problems (R. F. Krueger, 1999). MCTFR research has helped to explicate the comorbid nature of SUDs in several important ways. Here we highlight two. First, we have shown that SUDs are associated not only with mental health and substance abuse problems but also with extremes of normal-range variation in personality. Second, SUD comorbidities can be largely accounted for by a limited number of broad underlying dimensions of risk.

\section{The Contribution of Personality to the Development of SUDs}

While the notion that there exists a configuration of personality characteristics that uniquely determines SUD risk (i.e., the 'addictive personality') has been soundly rejected (Sutker \& Allain, 1988), it is widely recognized that personality factors make important contributions to the development of SUDs (Cloninger, 1987; Kreek, Nielsen, Butelman, \& LaForge, 2005). In an early MCTFR cross-sectional study (McGue, Slutske, Taylor, \& Iacono, 1997) we showed that alcoholics differed from non-alcoholics in two broad dimensions of personality. First, alcoholics, and especially early-onset alcoholics, are consistently lower in personality indicators of Constraint, a broad dimension of personality that reflects the ability to inhibit predominant behavioral responses. Second, alcoholics are consistently higher in personality indicators of Negative Emotionality, a broad dimension of personality that reflects the tendency to experience psychological distress and negative mood states.

To establish the temporal sequencing underlying the association of SUDs with personality, we subsequently investigated whether personality factors predicted new SUD cases between the ages of 17 and 20 (Elkins, King, McGue, \& Iacono, 2006). Consistent with our crosssectional results, both Constraint and Negative Emotionality were associated with incident cases of nicotine dependence, alcohol abuse/dependence, and illicit drug abuse/dependence. As with the cross-sectional findings, the magnitude of effect was greater for Constraint than for Negative Emotionality. Although these longitudinal findings cannot unambiguously establish the causal basis for the association of personality factors with SUD risk, they do show that the association cannot be due entirely to the onset of SUDs leading to personality deviations. 
Research on normative personality development provides insight into why Constraint and Negative Emotionality are associated with SUD risk. Both these personality factors change normatively during the transition from adolescence to young adulthood. Specifically, levels of Constraint typically increase while Negative Emotionality typically decreases over this period. This developmental pattern has been labeled the "maturity principle" (Caspi, Roberts, \& Shiner, 2005), as the normative changes in personality that occur increase the likelihood that young adults will become productive contributors to society with stable and satisfying relationships with others. Thus delayed attainment of developmental milestones in early adulthood may be a risk factor for the development of an SUD. To explore this question further, we investigated how normative personality changes during the transition to early adulthood were related to risk of an alcohol use disorder (AUD) (Hicks, Durbin, Blonigen, Iacono, \& McGue, 2012). Consistent with the maturity principle hypothesis, we observed decreases in Negative Emotionality and increases in Constraint from late adolescence to early adulthood regardless of AUD status. The magnitude of these changes did, however, depend on AUD status, as AUD desistence between ages 17 and 24 was associated with greater rates of personality maturation while AUD persistence was associated with lower rates of personality maturation.

In Hicks et al. (2012) we further showed that the personality characteristics that predict AUD onset and course were evident by age 11, well before the vast majority of individuals in the sample had initiated substance use. In another prospective investigation aimed at identifying the early behavioral indicators of SUD risk, we showed that the initiation and progression of substance use in middle adolescence were both associated with age-11 externalizing and internalizing psychopathology (King, Iacono, \& McGue, 2004). Moreover, the magnitude of the association was markedly stronger for indicators of externalizing than internalizing. Although this study did not explicitly deal with personality, we had shown in earlier research that personality indicators of Constraint map specifically on externalizing psychopathology, while personality indicators of Negative Emotionality map specifically on internalizing (R.F. Krueger, McGue, \& Iacono, 2001). Thus in aggregate, MCTFR personality research has shown that: 1) two dimensions of personality are associated with SUD onset and course; 2) these personality deviations predate substance use initiation; 3) the strength of association is consistently stronger for one of the dimensions (Constraint) than the other (Negative Emotionality); and 4) these two dimensions of personality map onto the externalizing and internalizing dimensions of psychopathology, respectively.

\section{The Dimensional Basis for SUD Comorbidity}

Building on a model of psychopathology that has emerged from more than 30 years of research with childhood disorders (Achenbach \& Edelbrock, 1978), addictions researchers have shown that the comorbidities involving common mental disorders and SUDs can be accounted for by the existence of underlying continuous dimensions of risk. Two underlying dimensions have been posited. First, and most prominently in the SUD research field, is externalizing psychopathology. In a MCTFR study, Krueger et al. (2002) showed that the associations among multiple quantitative indicators of substance dependence, antisocial behavior and the personality trait of (low) Constraint could be accounted for by a single underlying dimension of risk, labeled externalizing psychopathology. Similar evidence for 
the existence of a continuously distributed dimension of externalizing risk that could account for SUD associations has been reported by several other groups including Young et al. (2000), Vollebergh et al. (2001), and Kendler et al. (2003).

Left unaccounted for by this research on the latent dimension of externalizing psychopathology are the comorbidities of SUDs with internalizing psychopathology and related personality traits. These latter comorbidities appear to arise indirectly. That is, the comorbidities of SUDs with internalizing forms of psychopathology such as depression and anxiety disorders are due to a higher-order correlation that exists between externalizing and internalizing psychopathology. This model is illustrated in Figure 3.

Figure 3 also serves to highlight one critical feature of latent dimensional model of SUDs: Although SUDs are included as part of the externalizing spectrum, SUDs cannot be reduced to externalizing psychopathology. That is, each SUD is hypothesized to be a manifestation of two factors. The first, or general factor, is due to the loading of externalizing on SUD risk. It is this general factor that accounts for the features of SUDs that are shared with other disorders and with personality. The second, or specific factor, is due to aspects of SUD risk that are not accounted for by the common factor and so help to distinguish one specific SUD from the others as well as from other mental health problems. The notion that there are both common and specific processes that underlie SUD risk has provided a very valuable framework for evaluating alternatives models of the origins of SUDs (Iacono, Malone, \& McGue, 2008; Young, Rhee, Stallings, Corley, \& Hewitt, 2006).

\section{The Familial Nature of SUDs}

A second salient feature of SUDs is that they aggregate in families. Indeed, among psychiatric disorders SUDs have one of the highest rates of familial transmission. For example, Merikangas et al. (1998) reported an 8-fold increase in risk of a drug use disorder among the first-degree relatives of index cases with a drug use diagnosis as compared to controls. While family studies have consistently documented the familial nature of SUDs, it is important to recognize that these studies alone cannot resolve the separate contributions of genetic and environmental factors to the intergenerational transmission of SUDs. Genetically-informed studies are needed. The Merikangas et al. (1998) study also serves to highlight a second question to emerge from family research on SUDs; namely, to what extent does the familial transmission of SUDs owe to general versus specific processes. Merikangas et al. (1998) reported that alcoholism in the index case was not associated with an increased risk of a drug use diagnosis in relatives, suggesting specificity in familial transmission. Alternatively, other family studies of SUDs have reported evidence consistent with general transmission processes (Rounsaville et al., 1991) as well as both general and specific processes (Bierut et al., 1998). MCTFR research has helped to characterize general and specific processes in the familial transmission of SUDs as well as estimate the genetic and environmental contributions to these processes.

\section{The Inheritance of SUDs, General and Specific Processes}

Figure 4 gives findings from a biometric analysis of multiple indicators of disinhibited psychopathology from the older cohort of the MTFS by Krueger et al. (R. F. Krueger et al., 
2002). The phenotypic associations among quantitative measures of adult antisocial behavior, conduct disorder, alcohol dependence, drug dependence, and the personality trait of constraint (reverse scored) could be accounted for by a single general externalizing factor. Significantly, the externalizing factor is highly heritable $\left(\mathrm{a}^{2}=.81\right)$, suggesting that individuals inherit a general liability to engage in externalizing behavior but how that liability is manifested, e.g., as drug abuse, antisocial behavior, or low constraint, depends on phenotype-specific factors. That is, from 39\% (for adult antisocial behavior) to $78 \%$ (for low constraint) of the variance in the specific phenotypes is not accounted for by the general factor. Although much of the phenotype-specific variance is environmental in origin, implying that the specific phenotypic manifestations are largely environmentally shaped, $13 \%$ of the phenotypic variance in both alcohol dependence and drug dependence was attributed to specific genetic factors. Consequently, while these findings imply that much of the genetic liability for SUDs is attributable to the inheritance of general externalizing, there are genetic factors that also convey specific risk to either alcohol or drug abuse.

These findings were recently extended in an analysis utilizing all MCTFR participants assessed on five facets of externalizing behavior: nicotine, alcohol consumption, alcohol dependence, illicit drugs, and non-substance related behavioral disinhibition (Hicks, Schalet, Malone, Iacono, \& McGue, 2011). The general factor accounted for a large portion of the variance on each of the individual indicators (ranging from $71 \%$ for illicit drugs to $81 \%$ for behavioral disinhibition). As was the case with the earlier study by Krueger et al. (2002), genetic influences on each of the individual indicators were attributable largely to the heritability of the general factor. Nonetheless, there was evidence for phenotypic-specific genetic effects, which accounted for approximately $10 \%$ of the variance on each of the indicators.

The analyses by Krueger et al (2002) and Hicks et al. (2011) were based primarily on twins or other intragenerational relative pairs, raising the question as to whether the intergenerational, parent-offspring transmission of externalizing disorders can also be accounted for by the transmission of the general factor. Utilizing the MTFS sample of 17year old twins and their biological parents, Hicks et al. (2004) investigated the intergenerational transmission of four indicators of externalizing psychopathology; namely, symptom counts of: conduct disorder, adult antisocial behavior, alcohol dependence and drug dependence. Consistent with analyses based on twins alone, the intergenerational transmission of the four externalizing indicators could be accounted for by a general factor, which was highly heritable (estimate of $80 \%$ ).

\section{Genetic and Environmental Contributions to the Intergenerational Transmission of SUDs}

The SIBS sample, which includes both adopted and non-adopted families, provides a unique opportunity to investigate genetic and environmental contributions to the intergenerational transmission of SUDs. The study by Keyes et al. (2008) on parent-offspring similarity for smoking provides a useful illustration. There is a large epidemiological literature showing that parents who smoke are more likely to have offspring who smoke than parents who do not smoke (Leonardi-Bee, Jere, \& Britton, 2011). What is unclear, however, is whether parent-offspring similarity for smoking reflects environmental mechanisms, genetic 
mechanisms, or both. In SIBS, we found significant parent-offspring resemblance for smoking in both adopted (odds ratio $[\mathrm{OR}]=1.68)$ and non-adopted $(\mathrm{OR}=4.17)$ families. The significant parent smoking effect in adopted families implicates environmental mechanisms of transmission. The greater effect among non-adopted (i.e., biological) than adopted families implicates genetic mechanisms as well.

Parental smoking is associated with other indicators of externalizing behavior in addition to offspring smoking, although most of the relevant research showing this is based specifically on the effects of maternal smoking during pregnancy (Fergusson, Woodward, \& Horwood, 1998). Nonetheless, the association of parent smoking with multiple indicators of offspring externalizing raises the possibility that parent smoking effects may be the result of the generalized transmission of externalizing psychopathology rather than a specific environmental consequence of having a smoking parent. Consistent with the previous literature, in non-adopted families we found parent smoking to be significantly associated with multiple indicators of offspring externalizing, including symptoms of disruptive childhood disorders, delinquency, and permissive attitudes towards antisocial and aggressive behavior. In adopted families none of these associations with other indicators of offspring externalizing were significant. These results when combined with those on parent smoking suggest that parent smoking effects reflect two alternative pathways to risk (Figure 5): 1) an environmentally mediated pathway whereby parent smoking specifically increases risk of offspring smoking; and 2) a genetically mediated pathway whereby parent smoking is associated with multiple indicators of externalizing psychopathology.

\section{The Developmental Nature of SUDs}

Most individuals initiate their use of substances in adolescence, usually starting with either alcohol or nicotine. There is, however, marked variability in the age of that initial experience (Johnston, O'Malley, Bachman, \& Schulenberg, 2006). Normatively, initiation is followed by rapid escalation in substance use, which peaks in late adolescence through the early $20 \mathrm{~s}$ and begins to decline in the late 20s (Chen \& Kandel, 1995). Because of their longitudinal structure, the MCTFR samples are uniquely positioned to inform developmental models of SUDs. Figure 6 shows that normative developmental patterns of substance use are evident in the MCTFR and help to differentiate individuals who develop an SUD from those who do not. In this section we highlight two specific contributions of MCTFR research to developmental models of SUDs.

\section{The association between early substance use and adult substance abuse}

In a highly cited study, Grant and Dawson (1997) reported that rate of alcoholism in middleage adults was substantially higher among individuals who had initiated their alcohol use prior to age 15 as compared to those who had waited to first try alcohol until they were older than 20. Subsequent research by the same research team similarly showed that early nicotine use was associated with nicotine dependence (B F Grant, 1998) and early drug use with drug dependence (B. F. Grant \& Dawson, 1998).

Figure 7 illustrates two alternative models for the association of early adolescent substance use with adult SUDs. In Model A, early substance use is hypothesized to have a causal 
effect on risk of developing an SUD in adulthood. This effect may be direct, as might result, for example, because adolescents are susceptible to drinking excessively due to their diminished sensitivity to the negative and heightened sensitivity to the positive consequences of drinking (Cha, Li, Wilson, \& Swartzwelder, 2006; Maldonado, Finkbeiner, $\&$ Kirstein, 2008). The causal effect may also be an indirect, a consequence of the effect of early substance use on course of neurological (Spear, 2013) and social (Dewit, Adlaf, Offord, \& Ogborne, 2000) development in adolescence. Under Model B, the association between early substance use and adult SUD risk is non-causal. It is hypothesized to arise because early substance use and an SUD are both indicators of externalizing, albeit at different developmental stages. In this case, the correlation between the two indicators is a consequence of the longitudinal stability of externalizing.

We investigated the basis for the association of early adolescent problem behavior with adult mental health and SUDs in the older cohort of the MTFS (McGue \& Iacono, 2005). Five indicators of problem behavior before the age of 15 (alcohol use, nicotine use, illicit drug use, police contact, and sexual intercourse) were each significantly associated with five different clinical disorders in adulthood (nicotine dependence, alcohol abuse/dependence, illicit drug abuse/dependence, antisocial personality [ASPD], and major depression). Early alcohol use, for example, was not only associated with an adult alcohol use disorder, it was also associated with elevated rates of nicotine dependence, an illicit drug use disorder, ASPD and major depression. Alternatively, risk of alcohol use disorder was elevated not only among early drinkers but also among early smokers, early sexual initiators, etc. We confirmed the generality of the association between the early indicators and adult disorders by showing that a general factor of early adolescent problem behavior, which loaded on each of the five early indicators, was correlated .75 with a general factor of adult externalizing, which loaded on all of the disorders other than major depression.

The study thus provides support for the general process indicated in Model B of Figure 7. The study also provided evidence in support of Model A. That is, we found evidence for substance-specific effects in addition to the general process. For example, the association between adolescent smoking and adult nicotine dependence could not be accounted for entirely by a correlation between the two general factors. The portion of early smoking that was not accounted for by the general factor (i.e., the residual) was correlated with the residual for nicotine dependence. To further explore the question of specificity of effects and especially whether those effects are consistent with causality, we used the cotwin control (CTC) design in the study by Irons et al. (submitted). One of the greatest challenges facing substance use researchers is the drawing of strong causal inferences from the analysis of observational data only. Twin studies can help meet this challenge. Specifically, comparing outcomes within twin pairs discordant for exposure (here early substance use) can approximate the alternative outcomes that are the basis for causal inference under the counterfactual model (McGue, Osler, \& Christensen, 2010). The logic of the CTC design is easiest to see with MZ twins discordant on exposure. Within discordant pairs, the twin who is unexposed is matched to the exposed twin on genetic background and rearing environment and so provides an approximation to what the exposed twin would have looked like if he or she had not been exposed (i.e., the counterfactual). The strength of the CTC 
design is that the unexposed twin controls for confounders regardless of whether those confounders are directly measured in the study.

In Irons et al. (submitted), within MZ twin pairs discordant for alcohol use before age 15, the early using twin drank more and was more likely to use other drugs at age 24 than the non-early using twin. This observation is consistent with early alcohol use having a causal effect on adult outcomes, strengthening the inference by showing an early-drinking effect even when genetic and the environmental factors shared by MZ twins are taken into account. Thus MCTFR research provides support for both of the models described in Figure 7. Early substance use appears to be associated with mental and substance abuse problems in adulthood both because it is an indicator of general externalizing behavior and because early use appears to have a causal influence on later outcomes.

\section{Developmental changes in the contribution of genetic and environmental factors to substance use outcomes}

One of the most consistent findings to emerge from the behavioral genetic literature is that genetic and environmental contributions to individual differences in behavior are not fixed but rather can change across development. In particular, for many traits the importance of genetic factors appears to increase with age as the contribution of shared environmental influences declines (Bergen, Gardner, \& Kendler, 2007). The decline in shared environmental influences can be attributed to the diminishing impact of the rearing home. The increase in genetic influences can be attributed to individuals gaining greater control over the environments they experience and exerting that control in a way that is consistent with, and so amplifies the phenotypic effect of, their underlying genetically influenced dispositions.

In Derringer et al. (2007) we showed that the heritability of substance use involvement increased from .10 at age 11 , to .53 at age 14 , to .66 at age 17 in males. In females the comparable values were $.12, .24$ and .41 . As with other behavioral genetic studies of substance-related phenotypes (Rose, Dick, Viken, \& Kaprio, 2001), we find that the contribution of genetic factors to individual differences in substance use increases with age. It is useful to ask how the changing pattern of genetic influences relates to the general and specific processes that underlie substance use and abuse. In a subsequent study of the cooccurrence of symptoms of alcohol, marijuana and nicotine dependence, we found that the relative contribution of genetic factors at the general factor level declined continuously and markedly between age 14 and 29, while the contribution of non-shared environmental factors increased with age (Vrieze, Hicks, Iacono, \& McGue, 2012). Taken together, these two studies indicate that the importance of substance-specific factors increases with age as genetic contributions at the general factor level decline.

A well-studied polymorphism in the aldehyde dehydrogenase (ALDH2) gene provides a useful illustration of the shifting pattern of specific genetic influences with age. Two enzymes contribute to the metabolism of ethanol. In the first step, ethanol is converted to acetaldehyde by the enzyme alcohol dehydrogenase (ADH), and in the second acetaldehyde is converted to acetate by ALDH2. Since most of the dysphoric effects associated with drinking are associated with acetaldehyde levels, genes that code for a fast version of ADH 
or a slow version of ALDH2 should be protective against drinking heavily. Consistent with this expectation, a mutation that results in an inert version of ALDH2, and which occurs only in East Asians, is associated with markedly reduced rates of alcoholism (Luczak, Glatt, $\&$ Wall, 2006).

Most of the relevant research on the protective variant in the gene coding for ALDH2 is based on adults, however. Irons et al. (Irons, Iacono, Oetting, \& McGue, 2012) used a sample 356 adopted East Asians from SIBS to explore how the specific effect of ALDH2 on drinking shifted with age. The sample had been assessed multiple times spanning adolescence through early adulthood. In adolescence, there was little evidence of a protective effect of the deficient version of the ALDH2 enzyme. Beginning at about age 19 and increasing through the mid-20s, however, the ALDH2 allele became increasingly protective.

\section{Identifying the Specific Genetic Variants that Underlie SUD Risk}

The heritability of SUDs implies that there are inherited differences in the DNA sequence that contribute to SUD risk. Identifying these variants would greatly advance our understanding of the biological basis of addiction and provide insights into developing effective interventions. Gene-identification for complex phenotypes such as SUDs has, however, been difficult and progress slower than initially anticipated. Failure to replicate initially promising reports has been the norm for behavioral and non-behavioral phenotypes alike (Ioannidis, Ntzani, Trikalinos, \& Contopoulos-Ioannidis, 2001). Nonetheless, some progress has been made with candidate-gene studies of substance related phenotypes, with replicable associations reflecting both general (e.g., the effect of GABA system variants on multiple indicators of externalizing psychopathology) and specific (e.g., ALDH2 and alcoholism) processes being reported (McGue \& Irons, 2013).

Recently an alternative to the standard candidate-gene approach has emerged. Rather than assay one or a small number of genes, as is typical in a candidate-gene study, in a genomewide association study (GWAS) the whole genome is assayed by genotyping 500,000 or more common SNP (single nucleotide polymorphism) variants. Since the inception of this strategy in 2007, GWAS has resulted in the identification of thousands of genetic variants for hundreds of medically relevant phenotypes (Visscher, Brown, McCarthy, \& Yang, 2012). GWAS has also been successful in identifying genetic variants underlying behavioral phenotypes, most notably schizophrenia (Ripke et al., 2013).

More than 8000 MCTFR participants have been genotyped on more than 500,000 SNP markers(Miller et al., 2012) and GWAS analyses completed on multiple indicators of externalizing psychopathology and substance abuse including separate measures of use/ abuse of alcohol, nicotine, and illicit drugs (McGue et al., 2013). To control for the testing of multiple SNP markers, the accepted p-value threshold in a GWAS is $5 \times 10^{-8}$. At this threshold none of the more than half million SNPs was significantly associated with any of the multiple indicators of externalizing psychopathology. Although the failure to find significant associations in a sample of several thousand individuals may seem surprising, it is consistent with the emerging picture of the genetic architecture of complex phenotypes, 
such as substance related phenotypes. Specifically, the past 7 years of GWAS research has revealed that most complex phenotypes are characterized by two features. First, the phenotypic effect of any particular genetic variant is likely to be very small. For example, for quantitative traits, it is rare to see variants that account for as much as $0.3 \%$ of trait variance, and most have much smaller phenotypic effects than that. Reliable detection of variants that account for such a small percentage of variance will require massive sample sizes, especially given the GWAS standard of $\mathrm{p}<5 \times 10^{-8}$. As a consequence, human geneticists have established consortia whose goal is to achieve very large sample sizes, in many cases 100,000 or more, in order to detect these small effects. In light of this finding, the failure to identify any variants in the MCTFR is not unexpected.

The second feature of the genetic architecture of complex phenotypes is essentially a corollary of the first. For any given phenotype, the number of relevant genetic variants is likely to number in the hundreds or more likely thousands. Even with large sample sizes, consortia have been able to identify only a small proportion of the expected number of relevant variants. In schizophrenia, for example, a combined sample of 21,000 cases and 38,000 controls identified 22 specific genetic associations (Ripke et al., 2013). Of greater relevance here, in the tobacco consortia a combined sample approaching 100,000 yielded a few significant associations (Thorgeirsson et al., 2010). Similarly, a meta-analysis of GWAS of alcohol consumption totaling nearly 50,000 individuals reported one significant association (Schumann et al., 2011). As a consequence, known variants from GWAS account for only a small percentage of heritable variance for most phenotypes. Most of the genetic variance remains missing (Manolio et al., 2009).

\section{Developmental Models of Substance Use Disorders Informed by Behavioral Genetic Research}

Behavioral genetic research has established several key features of the development of SUDs. First, we can distinguish the separate contributions of general and specific factors to the development of SUDs. General risk is conveyed by a general disposition towards externalizing or disinhibitory psychopathology. It manifests early in life, prior to substance use onset, as childhood disruptive disorders, personality characteristics marked by low selfcontrol, and multiple indicators of adolescent problem behavior. The general disinhibitory process increases risk for all SUDs; contributions at the specific level serve to distinguish risk of one SUD from another. Support for the existence of specific processes comes from the observation that early substance use in adolescence appears to increase risk of the comparable SUD in adulthood over and above its serving as an indicator of externalizing psychopathology. Research on ALDH2 further suggests that the specific reaction individuals have to a substance may be an important contributor to substance-specific risk.

Second, behavioral genetic research indicates that SUDs are moderately heritable. The heritability of SUDs owes largely to the heritability of the common factor. Nonetheless, the heritable contribution of the general factor to SUD risk appears to shift with age. In adolescence a greater proportion of SUD variance is attributable to the general factor than in adulthood, when substance-specific genetic influences appear to grow in importance. Finally, it appears that the genetic diathesis underlying SUD risk is attributable to hundreds 
or maybe even thousands of genetic variants each of which has a very small effect on SUD risk. Detecting these variants will require very large sample sizes.

One feature of the genetic epidemiology of SUDs that we have not specifically commented on here concerns the contribution of gene-environment interaction (GxE) to SUD risk. As reflected by the diathesis-stress model, GxE is thought to play a fundamental role in the development behavioral and substance use disorders. That is, individuals are thought to inherit some level of vulnerability (i.e., the diathesis), but whether that vulnerability manifests as a disorder will depend on the environment they are exposed to (i.e., the stressor). Individuals who inherit a low level of vulnerability are relatively insensitive to the environment, they have low risk of the disorder regardless of the environment they are reared in. Alternatively, individuals who inherit a high level of vulnerability have heightened sensitivity to the environment. They are unlikely to develop the disorder if they experience a protective environment but highly likely to experience the disorder if reared in a provocative environment.

Research from the MCTFR has shown that genetic effects on externalizing psychopathology, including SUDs, are consistently stronger in a high-risk versus a low-risk environment, indirectly supporting the diathesis-stress model of SUDs (Hicks, South, DiRago, Iacono, \& McGue, 2009). Direct support would require that we are able to directly assay genetic risk at the DNA sequence level. As discussed previously, we have not yet identified many of the specific genetic variants that influence SUD risk, even though progress is being made. Until we know more about the genetic diathesis, it will be difficult to rigorously evaluate GxE contributions to the development of SUDs.

\section{References}

Achenbach TM, Edelbrock CS. Classification of child psychopathology: Review and analysis of empirical efforts. [Review]. Psychological Bulletin. 1978; 85(6):1275-1301. [PubMed: 366649]

Bergen SE, Gardner CO, Kendler KS. Age-related changes in heritability of behavioral phenotypes over adolescence and young adulthood: A meta-analysis. Twin Research and Human Genetics. 2007; 10(3):423-433. [PubMed: 17564500]

Bierut LJ, Dinwiddie SH, Begleiter H, Crowe RR, Hesselbrock V, Nurnberger JI Jr. Reich T. Familial transmission of substance dependence: alcohol, marijuana, cocaine, and habitual smoking: a report from the Collaborative Study on the Genetics of Alcoholism. Archives of General Psychiatry. 1998; 55(11):982-988. [PubMed: 9819066]

Caspi A, Moffitt TE, Newman DL, Silva PA. Behavioural observations at age 3 predict adult psychiatric disorders: Longitudinal evidence from a birth cohort. Archives of General Psychiatry. 1996; 53:1033-1039. [PubMed: 8911226]

Caspi, A.; Roberts, BW.; Shiner, RL. Annual Review of Psychology. Vol. Vol. 56. Annual Reviews; Palo Alto: 2005. Personality development: Stability and change; p. 453-484.

Cha YM, Li Q, Wilson WA, Swartzwelder HS. Sedative and GABAergic effects of ethanol on male and female rats. Alcoholism-Clinical and Experimental Research. 2006; 30(1):113-118.

Chen K, Kandel DB. The natural history of drug use from adolescence to the mid-thirties in a general population sample. American Journal of Public Health. 1995; 85(1):41-47. [PubMed: 7832260]

Cloninger CR. Neurogenetic adaptive mechanisms in alcoholism. Science. 1987; 236:410-416. [PubMed: 2882604]

Derringer, JL.; Krueger, RF.; Iacono, WG.; McGue, M. Age and sex effects on the etiology of substance use in adolescents. 2007. manuscript in preparation 
Dewit DJ, Adlaf EM, Offord DR, Ogborne AC. Age at first alcohol use: A risk factor for the development of alcohol disorders. American Journal of Psychiatry. 2000; 157:745-750. [PubMed: 10784467]

Elkins IJ, King SM, McGue M, Iacono WG. Personality traits and the development of nicotine, alcohol, and illicit drug disorders: Prospective links from adolescence to young adulthood. Journal of Abnormal Psychology. 2006; 115(1):26-39. [PubMed: 16492093]

Fergusson DM, Woodward LJ, Horwood LJ. Maternal smoking during pregnancy and psychiatric adjustment in late adolescence. [Article]. Archives of General Psychiatry. 1998; 55(8):721-727. doi: 10.1001/archpsyc.55.8.721. [PubMed: 9707383]

Grant BF. Age at smoking onset and its association with alcohol consumption and DSM-IV alcohol abuse and dependence: Results from the National Longitudinal Alcohol Epidemiologic Survey. Journal of Substance Abuse. 1998; 10:59-73. [PubMed: 9720007]

Grant BF, Dawson DA. Age at onset of alcohol use and its association with DSM-IV alcohol abuse and dependence: Results from the National Longitudinal Alcohol Epidemiologic Survey. Journal of Substance Abuse. 1997; 9:103-110. [PubMed: 9494942]

Grant BF, Dawson DA. Age of onset of drug use and its association with DSM-IV drug abuse and dependence: Results from the National Longitudinal Alcohol Epidemiologic Survey. Journal of Substance Abuse. 1998; 10:163-173. [PubMed: 9854701]

Hicks BM, Durbin CE, Blonigen DM, Iacono WG, McGue M. Relationship between personality change and the onset and course of alcohol dependence in young adulthood. Addiction. 2012; 107(3):540-548. [PubMed: 21851441]

Hicks BM, Krueger RF, Iacono WG, McGue M, Patrick CJ. Family transmission and heritability of externalizing disorders - A twin-family study. Archives of General Psychiatry. 2004; 61(9):922928. [PubMed: 15351771]

Hicks BM, Schalet BD, Malone SM, Iacono WG, McGue M. Psychometric and Genetic Architecture of Substance Use Disorder and Behavioral Disinhibition Measures for Gene Association Studies. [Article]. Behavior Genetics. 2011; 41(4):459-475. doi: 10.1007/s10519-010-9417-2. [PubMed: 21153693]

Hicks BM, South SC, DiRago AC, Iacono WG, McGue M. Environmental Adversity and Increasing Genetic Risk for Externalizing Disorders. [Article]. Archives of General Psychiatry. 2009; 66(6): 640-648. [PubMed: 19487629]

Iacono WG, Carlson SR, Taylor J, Elkins IJ, McGue M. Behavioral disinhibition and the development of substance use disorders: Findings from the Minnesota Twin Family Study. Development and Psychopathology. 1999; 11:869-900. [PubMed: 10624730]

Iacono, WG.; Malone, SM.; McGue, M. Annual Review of Clinical Psychology. Vol. Vol. 4. Annual Reviews; Palo Alto: 2008. Behavioral disinhibition and the development of early-onset addiction: Common and specific influences; p. 325-348.

Ioannidis JP, Ntzani EE, Trikalinos TA, Contopoulos-Ioannidis DG. Replication validity of genetic association studies. Nature Genetics. 2001; 29:306-309. [PubMed: 11600885]

Irons, DE.; Iacono, WG.; McGue, M. Tests of the effects of adolescent early alcohol exposures on adult outcomes. (submitted)

Irons DE, Iacono WG, Oetting WS, McGue M. Developmental Trajectory and Environmental Moderation of the Effect of ALDH2 Polymorphism on Alcohol Use. [Article]. AlcoholismClinical and Experimental Research. 2012; 36(11):1882-1891. doi: 10.1111/j. 1530-0277.2012.01809.x.

Johnston, LD.; O'Malley, PM.; Bachman, JG.; Schulenberg, JE. Monitoring the Future national survey results on drug use, 1975-2005. Vol. Volume I: Secondary school students (NIH Publication No. 06-5883). National Institute on Drug Abuse; Bethesda, MD: 2006.

Kendler KS, Prescott CA, Myers J, Neale MC. The structure of genetic and environmental factors for common psychiatric and substance use disorders in men and women. Archives of General Psychiatry. 2003; 60:929-937. [PubMed: 12963675]

Keyes M, Legrand LN, Iacono WG, McGue M. Parent smoking and adolescent problem behavior: An adoption study of general and specific effects. American Journal of Psychiatry. 2008 in press. 
Keyes MA, Malone SM, Elkins IJ, Legrand LN, McGue M, Iacono WG. The Enrichment Study of the Minnesota Twin Family Study: Increasing the yield of twin families at high risk for externalizing psychopathology. Twin Research and Human Genetics. 2009; 12(5):489-501. [PubMed: 19803776]

King SM, Iacono WG, McGue M. Childhood externalizing and internalizing psychopathology in prediction of early substance use. Addiction. 2004; 99:1548-1559. [PubMed: 15585046]

Kreek MJ, Nielsen DA, Butelman ER, LaForge KS. Genetic influences on impulsivity, risk taking, stress responsivity and vulnerability to drug abuse and addiction. Nature Neuroscience. 2005; 8(11):1450-1457. [PubMed: 16251987]

Krueger RF. The structure of common mental disorders. Archives of General Psychiatry. 1999; 56:921-926. [PubMed: 10530634]

Krueger RF, Hicks BM, Patrick CJ, Carlson SR, Iacono WG, McGue M. Etiologic connections among substance dependence, antisocial behavior, and personality: modeling the externalizing spectrum. Journal of Abnormal Psychology. 2002; 111(3):411-424. [PubMed: 12150417]

Krueger RF, McGue M, Iacono WG. The higher-order structure of common DSM mental disorders: Internalization, externalization, and their connections to personality. Personality and Individual Differences. 2001; 30:1245-1259.

Leonardi-Bee J, Jere ML, Britton J. Exposure to parental and sibling smoking and the risk of smoking uptake in childhood and adolescence: a systematic review and meta-analysis. [Review]. Thorax. 2011; 66(10):847-855. doi: 10.1136/thx.2010.153379. [PubMed: 21325144]

Luczak SE, Glatt SJ, Wall TL. Meta-analyses of ALDH2 and ADH1B with alcohol dependence in Asians. Psychological Bulletin. 2006; 132(4):607-621. [PubMed: 16822169]

Maldonado AM, Finkbeiner LM, Kirstein CL. Social interaction and partner familiarity differentially alter voluntary ethanol intake in adolescent male and female rats. [Article]. Alcohol. 2008; 42(8): 641-648. doi: 10.1016/j.alcohol.2008.08.003. [PubMed: 18922665]

Manolio TA, Collins FS, Cox NJ, Goldstein DB, Hindorff LA, Hunter DJ, Visscher PM. Finding the missing heritability of complex diseases. Nature. 2009; 461(7265):747-753. doi: 10.1038/ nature08494. [PubMed: 19812666]

Martinotti G, Carli V, Tedeschi D, Di Giannantonio M, Roy A, Janiri L, Sarchiapone M. Mono- and polysubstance dependent subjects differ on social factors, childhood trauma, personality, suicidal behaviour, and comorbid Axis I diagnoses. Addictive Behaviors. 2009; 34(9):790-793. doi: 10.1016/j.addbeh.2009.04.012. [PubMed: 19446962]

Masten AS, Faden VB, Zucker RA, Spear LP. Underage drinking: A developmental framework. Pediatrics. 2008; 121:S235-S251. doi: 10.1542/peds.2007-2243A. [PubMed: 18381492]

McGue M, Iacono WG. The association of early adolescent problem behavior with adult psychopathology. American Journal of Psychiatry. 2005; 162(6):1118-1124. [PubMed: 15930060]

McGue, M.; Irons, DE. Etiology. In: McCrady, BS.; Epstein, ES., editors. Addictions: A comprehensive guidebook. Oxford; New York: 2013. p. 36-72.

McGue M, Keyes M, Sharma A, Elkins I, Legrand L, Johnson W, Iacono WG. The environments of adopted and non-adopted youth: Evidence on range restriction from the Sibling Interaction and Behavior Study (SIBS). Behavior Genetics. 2007; 37(3):449-462. [PubMed: 17279339]

McGue M, Osler M, Christensen K. Causal inference and observational research: The utility of twins. Perspectives on Psychological Science. 2010; 5(5):546-556. [PubMed: 21593989]

McGue M, Slutske W, Taylor J, Iacono WG. Personality and substance use disorders: I. Effects of gender and alcoholism subtype. Alcoholism: Clinical and Experimental Research. 1997; 21:513520.

McGue M, Zhang YW, Miller MB, Basu S, Vrieze S, Hicks B, Iacono WG. A Genome-Wide Association Study of Behavioral Disinhibition. Behavior Genetics. 2013; 43(5):363-373. doi: 10.1007/s10519-013-9606-x. [PubMed: 23942779]

Merikangas KR, Stolar M, Stevens DE, Goulet J, Preisig MA, Fenton B, Rounsaville BJ. Familial transmission of substance use disorders. Arch Gen Psychiatry. 1998; 55(11):973-979. [PubMed: 9819065] 
Miller MB, Basu S, Cunningham J, Eskin E, Malone SM, Oetting WS, McGue M. The Minnesota Center for Twin and Family Research Genome-Wide Association Study. [Article]. Twin Research and Human Genetics. 2012; 15(6):767-774. doi: 10.1017/thg.2012.62. [PubMed: 23363460]

Ripke S, O'Dushlaine C, Chambert K, Moran JL, Kahler AK, Akterin S, Wellcome Trust Case Control, C. Genome-wide association analysis identifies 13 new risk loci for schizophrenia. [Article]. Nature Genetics. 2013; 45(10):1150-U1282. doi: 10.1038/ng.2742. [PubMed: 23974872]

Rose RJ, Dick DM, Viken RJ, Kaprio J. Gene-environment interaction in patterns of adolescent drinking: Regional residency moderates longitudinal influences on alcohol use. Alcoholism: Clinical and Experimental Research. 2001; 25(5):637-643.

Rounsaville BJ, Kosten TR, Weissman MM, Prusoff B, Pauls D, Anton SF, Merikangas KR. Psychiatric disorders in relatives of probands with opiate addiction. Archives of General Psychiatry. 1991; 48(1):33-42. [PubMed: 1984760]

Schumann G, Coin LJ, Lourdusamy A, Charoen P, Berger KH, Stacey D, Elliott P. Genome-wide association and genetic functional studies identify autism susceptibility candidate 2 gene (AUTS2) in the regulation of alcohol consumption. Proceedings of the National Academy of Sciences of the United States of America. 2011; 108(17):7119-7124. doi: 10.1073/pnas.1017288108. [PubMed: 21471458]

Spear L. The teenage brain: Adolescents and alcohol. Current Directions in Psychological Science. 2013; 22(2):152-157. [PubMed: 25309054]

Sutker PB, Allain AN. Issues in personality conceptualizations of addictive behaviors. [Review]. Journal of Consulting and Clinical Psychology. 1988; 56(2):172-182. doi: 10.1037/0022-006x. 56.2.172. [PubMed: 3286701]

Thorgeirsson TE, Gudbjartsson DF, Surakka I, Vink JM, Amin N, Geller F, Consortium, E. Sequence variants at CHRNB3-CHRNA6 and CYP2A6 affect smoking behavior. Nature Genetics. 2010; 42(5):448-U135. doi: 10.1038/ng.573. [PubMed: 20418888]

Visscher PM, Brown MA, McCarthy MI, Yang J. Five Years of GWAS Discovery. [Review]. American Journal of Human Genetics. 2012; 90(1):7-24. doi: 10.1016/j.ajhg.2011.11.029. [PubMed: 22243964]

Vollebergh WAM, Iedema J, Bijl RV, de Graaf R, Smit F, Ormel J. The structure and stability of common mental disorders - The NEMESIS Study. Archives of General Psychiatry. 2001; 58(6): 597-603. [PubMed: 11386990]

Vrieze SI, Hicks BM, Iacono WG, McGue M. Decline in Genetic Influence on the Co-Occurrence of Alcohol, Marijuana, and Nicotine Dependence Symptoms From Age 14 to 29. [Article]. American Journal of Psychiatry. 2012; 169(10):1073-1081. doi: 10.1176/appi.ajp.2012.11081268. [PubMed: 22983309]

Young SE, Rhee SH, Stallings MC, Corley RP, Hewitt JK. Genetic and environmental vulnerabilities underlying adolescent substance use and problem use: General or specific? Behavior Genetics. 2006; 36(4):603-615. [PubMed: 16619135]

Young SE, Stallings MC, Corley RP, Krauter KS, Hewitt JK. Genetic and environmental influences on behavioral disinhibition. American Journal of Medical Genetics (Neuropsychiatric Genetics). 2000; 96(5):684-695. [PubMed: 11054778] 


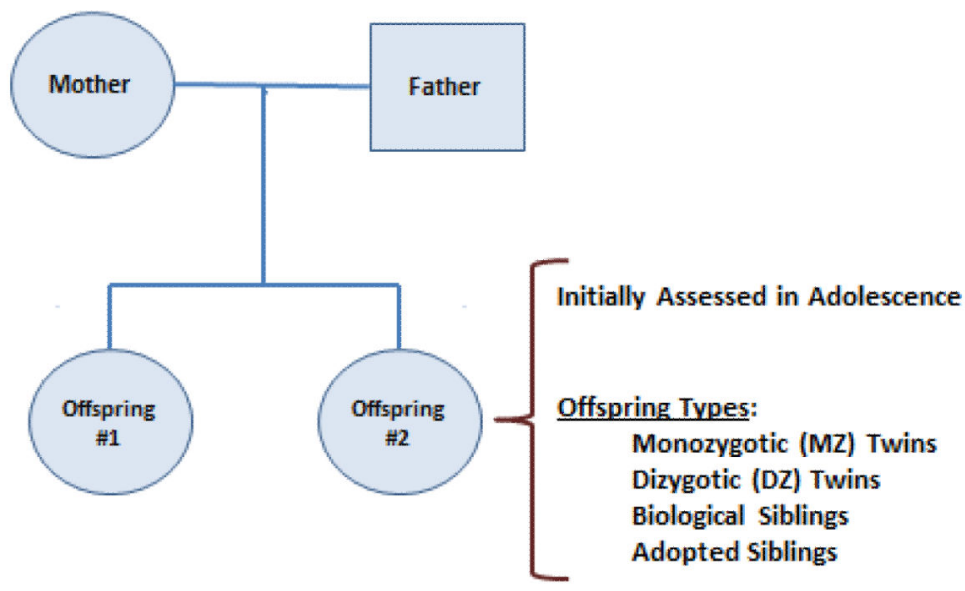

Figure 1.

The basic sampling unit used in Minnesota Twin Family Research, consisting of a sibling or twin pair, initially assessed in adolescence, and their rearing parents. 


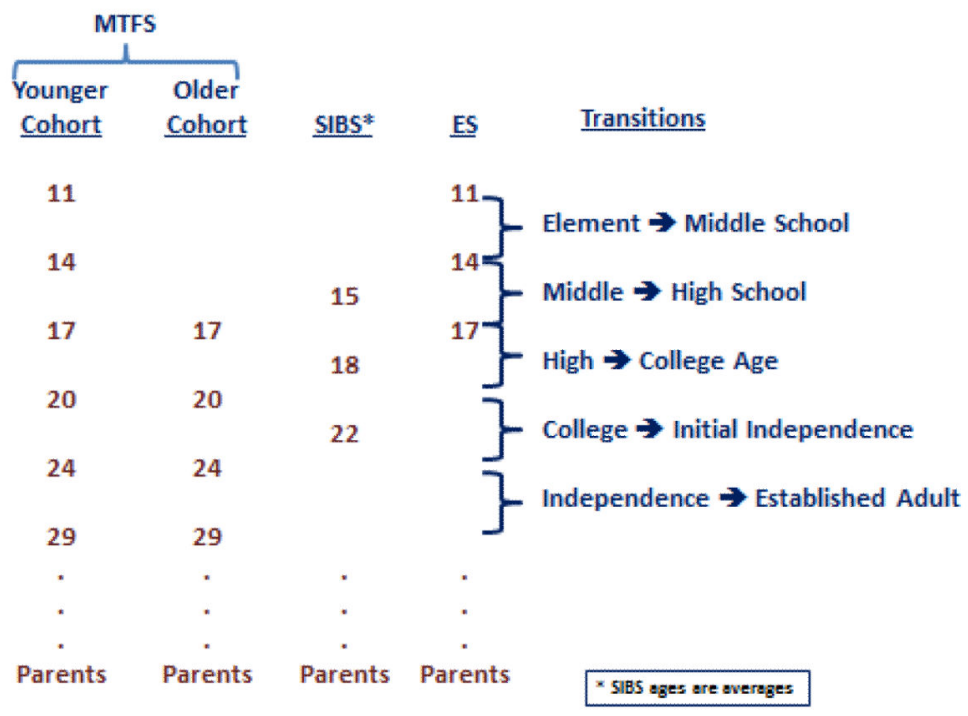

Figure 2.

Conceptual overview of the Minnesota Twin Family Research longitudinal design. Offspring assessments are timed to coincide with major transitions in the life of a young person. Parents provide an additional observation in mid-life. MTFS $=$ Minnesota Twin Family Study, SIBS = Sibling Interaction and Behavior Study, ES = Enrichment Study. 


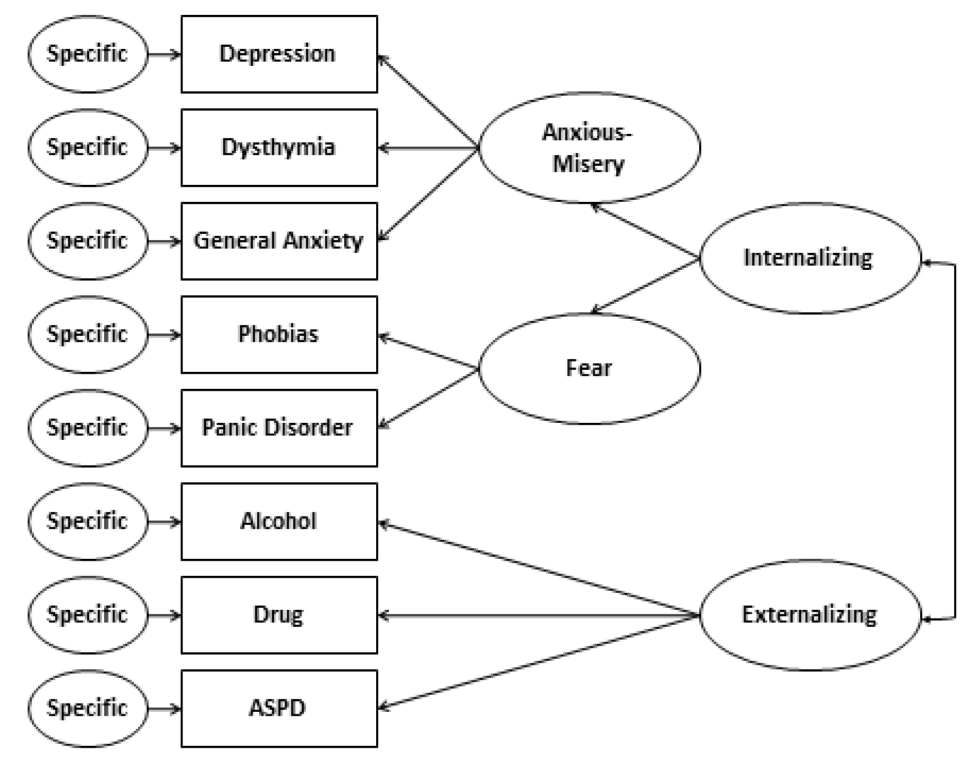

Figure 3.

Mapping substance use disorders onto the dimensions of internalizing and externalizing psychopathology. Model based on findings from Krueger (1999), Vollebergh et al. (2001), and Kendler et al.(2003). Figure reproduced with permission from McGue and Irons (2013). 


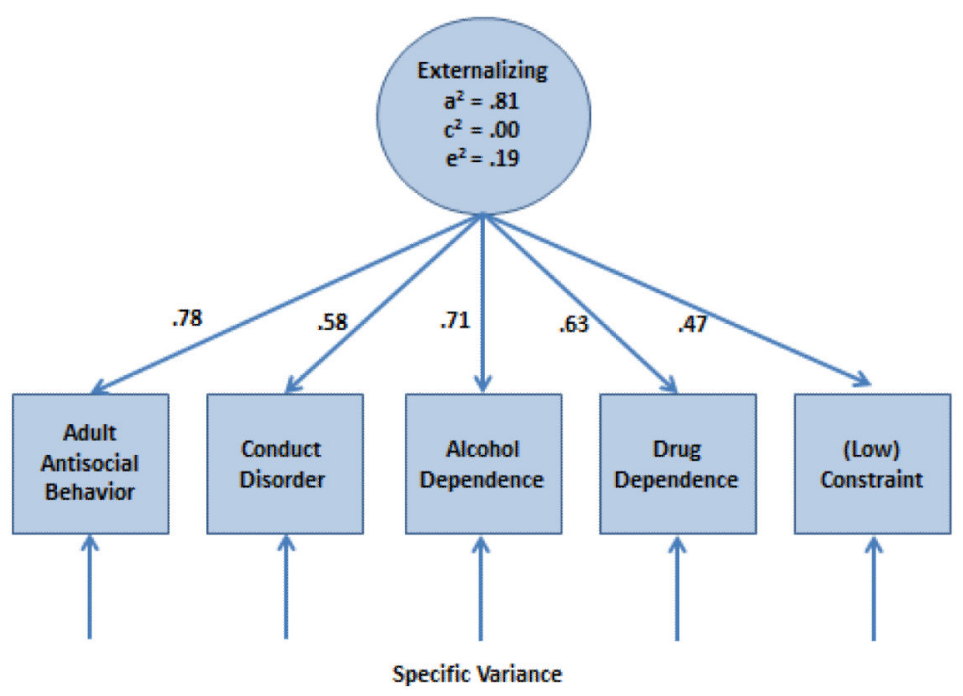

Figure 4.

Biometric latent model of externalizing psychopathology. The associations among the five observed phenotypes can be accounted for by a single externalizing factor with variance apportioned as $81 \%$ to additive genetic factors $\left(\mathrm{a}^{2}\right), 0 \%$ to shared environmental factors $\left(\mathrm{c}^{2}\right)$, and $19 \%$ to nonshared environmental factors $\left(\mathrm{e}^{2}\right)$. Based on findings from Krueger et al. (R. F. Krueger et al., 2002). 

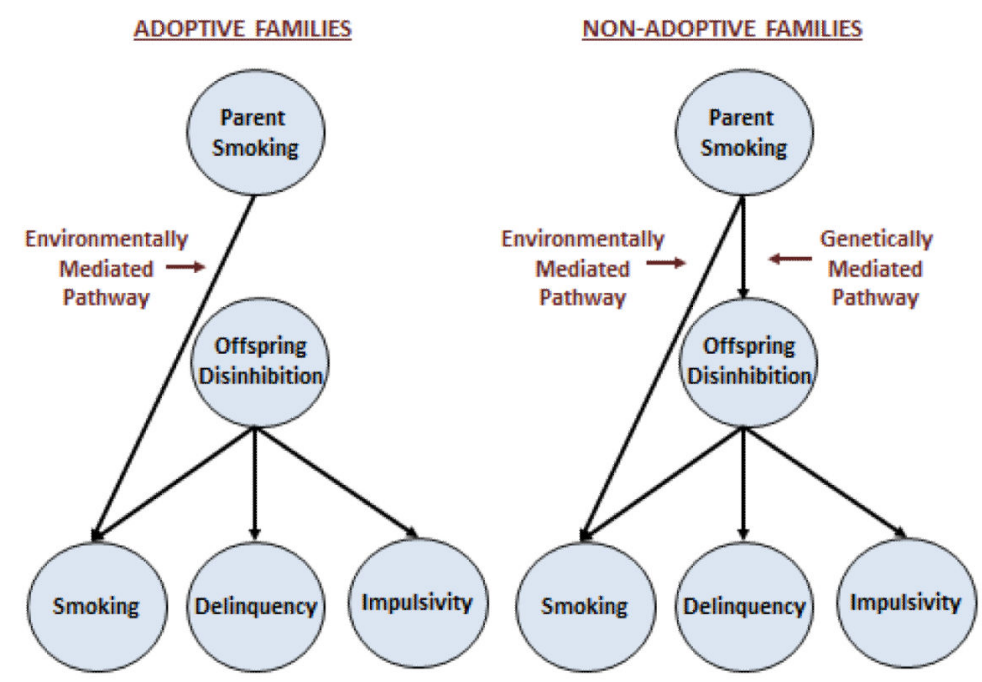

Figure 5.

The effect of parent smoking in adoptive and non-adoptive families. In adoptive families, parent smoking is associated only with offspring smoking, implicating an environmentally mediated pathway that is specific to smoking. In non-adoptive families, parent smoking is also associated with other indicators of offspring externalizing, implicating a genetically mediated general pathway. Figure reprinted from Keyes et al. (2008), with permission. 


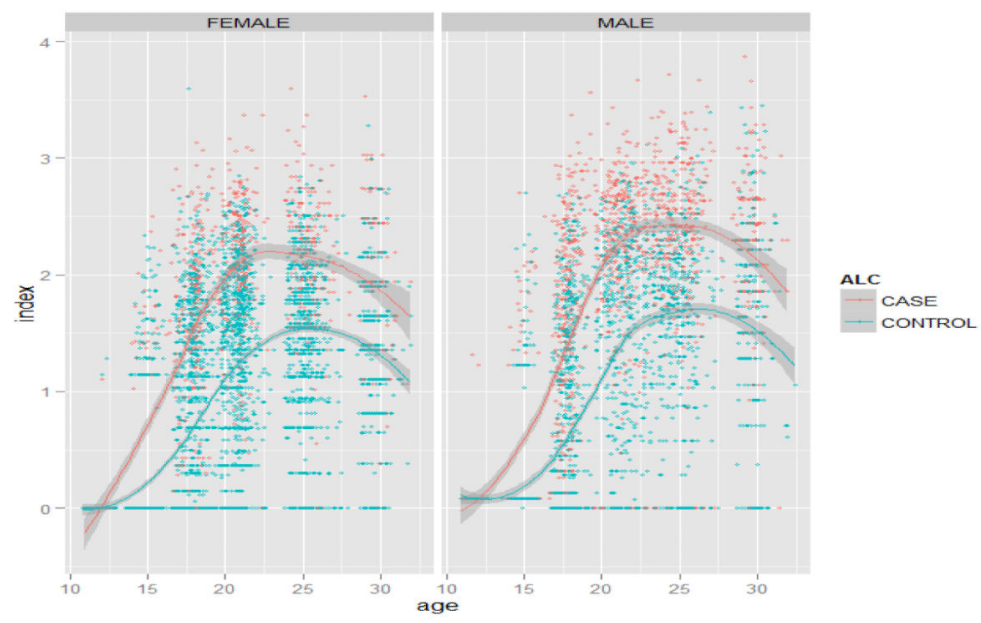

Figure 6.

Quantity-frequency drinking index as a function of age in the Minnesota Twin Family Study longitudinal samples. The index is scaled to have a standard deviation of 1.0. The lines represent the lowess-averaged trajectories for those who met lifetime criteria for Alcohol Dependence (cases) versus those who did not. The trajectories show that individuals who develop Alcohol Dependence tend not only to start drinking earlier but also accelerate more rapidly in their drinking in adolescence. 
A

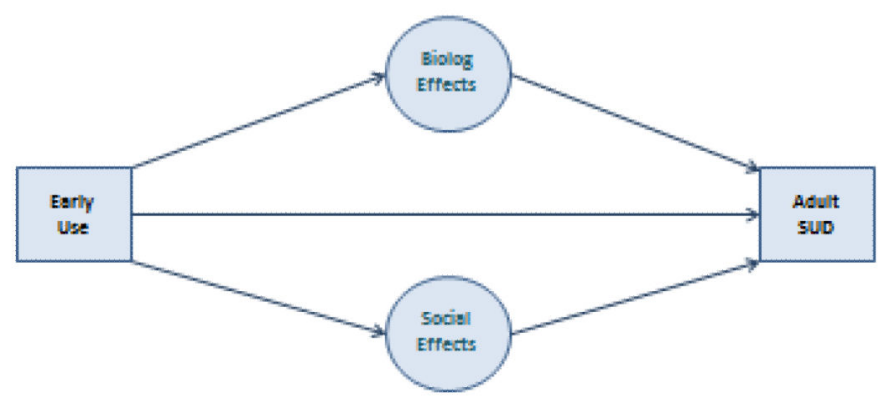

B

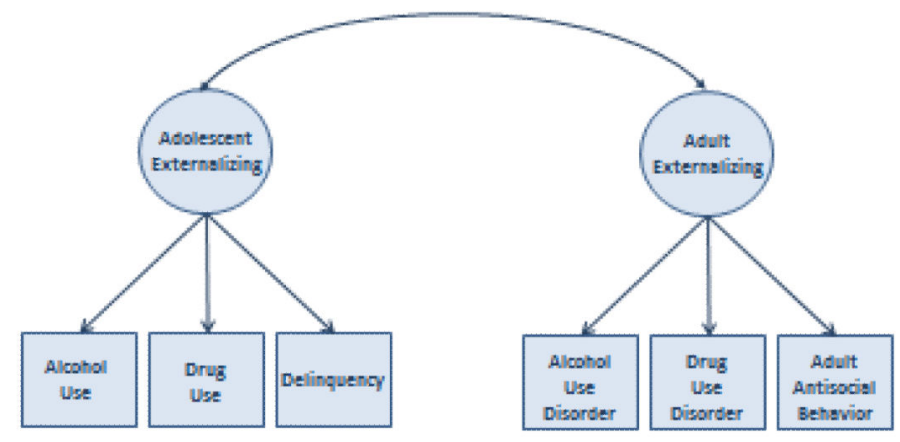

Figure 7.

Alternative models linking early substance use in adolescence with risk of a substance use disorder (SUD) in adulthood. Model A hypothesizes a causal influence of early substance use, while Model B hypothesizes that early substance use is associated with adult SUD because both are indicators of externalizing psychopathology. 
Table 1

A brief overview of the Minnesota Center for Twin and Family Research (MCTFR) studies

\begin{tabular}{lcll}
\hline Study & $\begin{array}{c}\text { Year } \\
\text { Started }\end{array}$ & $\begin{array}{l}\text { Twin/Sibling } \\
\text { Pairs }\end{array}$ & Longitudinal Design \\
\hline Minnesota Twin Family Study (MTFS) & 1990 & $\begin{array}{l}\text { 897 Monozygotic } \\
\text { 485 Dizygotic }\end{array}$ & $\begin{array}{l}\text { Two cohorts (initial age of 11 } \\
\text { or 17) followed every 3-4 } \\
\text { years through age-29 }\end{array}$ \\
$\begin{array}{l}\text { Sibling Interaction and Behavior Study } \\
\text { (SIBS) }\end{array}$ & 1998 & $\begin{array}{l}\text { 408 Adopted } \\
\text { 209 Full Biological }\end{array}$ & $\begin{array}{l}\text { Cross-sectional sample first } \\
\text { assessed in adolescence and } \\
\text { followed twice through early } \\
\text { adulthood }\end{array}$ \\
Enrichment Study (ES) & & 300 Monozygotic & $\begin{array}{l}\text { First assessed at age-11 and } \\
\text { followed at ages 14 and 17 }\end{array}$ \\
\hline
\end{tabular}




\section{Table 2}

Characteristics of participants in longitudinal studies at the Minnesota Center for Twin and Family Research. Each cell gives the number of relevant participants, their average age at that assessment, and the percentage of intake participants completing that assessment

\begin{tabular}{|c|c|c|c|c|}
\hline Assessment & $\begin{array}{c}\text { MTFS 11-Year-Old } \\
\text { Cohort } \\
\text { (N=761 families) }\end{array}$ & $\begin{array}{c}\text { MTFS 17-Year-Old } \\
\text { Cohort } \\
\text { (N=626 families) }\end{array}$ & $\begin{array}{c}E S \\
\text { (N=499 families) }\end{array}$ & $\begin{array}{c}\text { SIBS } \\
\text { (N=617 families) }\end{array}$ \\
\hline \multicolumn{5}{|c|}{ Offspring Assessments: } \\
\hline Intake & $\begin{array}{c}1527 \\
11.7 \\
(100 \%)\end{array}$ & $\begin{array}{c}1252 \\
17.5 \\
(100 \%)\end{array}$ & $\begin{array}{c}998 \\
11.9 \\
(100 \%)\end{array}$ & $\begin{array}{c}1232 \\
14.9 \\
(100 \%)\end{array}$ \\
\hline Follow-up \#1 & $\begin{array}{l}1409 \\
14.8 \\
(92 \%)\end{array}$ & $\begin{array}{c}1111 \\
20.7 \\
(89 \%)\end{array}$ & $\begin{array}{l}930 \\
15.1 \\
(93 \%)\end{array}$ & $\begin{array}{l}1158 \\
18.3 \\
(94 \%)\end{array}$ \\
\hline Follow-up \#2 & $\begin{array}{c}1325 \\
18.2 \\
(87 \%)\end{array}$ & $\begin{array}{c}1167 \\
24.7 \\
(93 \%)\end{array}$ & $\begin{array}{c}913 \\
17.9 \\
(91 \%)\end{array}$ & $\begin{array}{c}1128 \\
22.4 \\
(92 \%)\end{array}$ \\
\hline Follow-up \#3 & $\begin{array}{c}1339 \\
21.5 \\
(88 \%)\end{array}$ & $\begin{array}{l}1168 \\
29.6 \\
(93 \%)\end{array}$ & & \\
\hline Follow-up \#4 & $\begin{array}{c}1332 \\
25.3 \\
(87 \%)\end{array}$ & & & \\
\hline Follow-up \#5* & $\begin{array}{c}1321 \\
29.3 \\
(87 \%)^{*}\end{array}$ & & & \\
\hline \multicolumn{5}{|c|}{ Parent Assessment: } \\
\hline Intake - Mothers & $\begin{array}{c}761 \\
39.3\end{array}$ & $\begin{array}{l}626 \\
44.3\end{array}$ & $\begin{array}{l}497 \\
41.4\end{array}$ & $\begin{array}{l}613 \\
46.6\end{array}$ \\
\hline Intake - Fathers & $\begin{array}{l}744 \\
41.8\end{array}$ & $\begin{array}{l}595 \\
46.2\end{array}$ & $\begin{array}{l}439 \\
43.3\end{array}$ & $\begin{array}{l}549 \\
482\end{array}$ \\
\hline
\end{tabular}

